\title{
Assessment of Knowledge, Attitude and Practice of Health Professionals towards Adverse Drug Reaction Reporting and Factors Associated with Reporting
}

\author{
Welelaw Necho Mulatu ${ }^{1 *}$ and Alemayehu Worku² \\ ${ }^{1}$ USAID/DELIVER PROJECT, Addis Ababa, Ethiopia \\ ${ }^{2}$ Addis Continental Institute of Public Health, Addis Ababa, Ethiopia
}

\begin{abstract}
Purpose: Spontaneous reporting of adverse drug reactions (ADRs) is a significant activity to improve the safety of medicines and health care professionals are pivotal players. This study aims to assess the knowledge, attitude and practice of health professionals towards an adverse drug reaction reporting and factors associated with reporting.

Methods: Institutional based cross sectional study complemented with qualitative study was conducted from May to November, 2012 in Amhara region. Using a two stage cluster sampling technique, 708 participants were selected for the study. A pretested self-administered questionnaire was used for data collection. An in-depth interview was used to collect qualitative data. Multivariate binary logistic regression was used for the analysis.

Results: It was found that none of the respondents mentioned the national ADR reporting guideline as their source of information on ADR reporting. Based on the overall knowledge score, about two thirds $411(65.8 \%)$ of the respondents had insufficient knowledge on the ADR reporting system. A very small proportion of respondents 101(16.2\%) had ever reported ADR they encountered during their professional practice. Being participated in ADR related training [AOR: $1.82(1.10,3.10) 95 \% \mathrm{Cl}$ ], being introduced with ADR during college or university education and level of knowledge [AOR: $5.99(3.61,9.94) 95 \% \mathrm{Cl}$ ] are found to be significantly associated with ADR reporting.

Conclusion: The level of knowledge towards ADR reporting is low. ADR reporting practice is also low among health professionals. Hence, strategies need to be devised to create awareness among health professionals towards ADR reporting.
\end{abstract}

Keywords: Pharmacovigilance; ADR reporting; Knowledge; Attitude

\section{Introduction}

The World Health Organization (WHO) initiated an international drug monitoring program in 1968 to coordinate activities worldwide [1]. Pharmacovigilance is the science and activities relating to the detection, assessment, understanding and prevention of ADR or any other medicine related problem to improve the safety of medicines. According to WHO definition, an ADR is any noxious, unintended, and undesired effect of a drug, which occurs at doses used in humans for prophylaxis, diagnosis, or therapy [2]. A number of studies conducted worldwide indicated spontaneous reporting of ADRs as a corner stone for successful pharmacovigilance and highlighted the significance of the contribution of health professionals in this regard. However, under reporting is mentioned as a major issue for the spontaneous reporting, especially in African countries [3-8]. A study in Ethiopia also highlighted that only few reports are sent to the national pharmacovigilance center [9].

An ADR constitutes a major health problem for individuals as well as for the public and it has also socioeconomic consequences for the community. ADRs are responsible for about $5 \%$ to $20 \%$ of hospital admissions in the Europe and US and it is also one of the leading causes of death in developed countries; however, there is scarcity of information about its incidence in developing countries, especially those in Africa $[3,4,10]$.

ADR reports received by responsible organizations in different countries represent only a small percentage of adverse reactions that have occurred. Some studies estimated reporting rates to be as low as $1-10 \%[4,11]$. A systematic review to estimate the extent of underreporting of adverse drug reactions to spontaneous reporting systems revealed that the median under-reporting rate across the 37 studies was $94 \%[12]$.

A systematic review on determinants of reporting of ADRs worldwide showed that while personal and professional factors display a weak influence, the knowledge and attitudes of health professionals appear to be strongly related with reporting in a high proportion of studies [12-20].

Spontaneous reporting of ADRs remains the cornerstone of pharmacovigilance and it is important in maintaining patient safety However, the success of this activity is dependent on the frequency of reporting by the health care professionals. Ethiopia established its own pharmacovigilance system under Food, Medicine, and Health care Administration and Control Authority (FMHACA) in 2002 and became a member of the WHO program for international drug monitoring. The Ethiopian ADR reporting and monitoring center, coordinated the overall system since its establishment; the number of ADR reports received from healthcare providers to the center are very small $[9,21]$.

*Corresponding author: Welelaw Necho Mulatu, B. Pharm, Deliver Project, Health logistics management information system advisor at the Pharmaceutical Fund and Supplies Agency, PO: 1392, Addis Abeba 1110, Ethiopia, Fax: 251-11-467-23-67; Tel: +251 - 911 -737210, E-mail: wellela12@yahoo.com

Received May 23, 2014; Accepted June 19, 2014; Published June 27, 2014

Citation: Necho W, Worku A (2014) Assessment of Knowledge, Attitude and Practice of Health Professionals towards Adverse Drug Reaction Reporting and Factors Associated with Reporting. J Pharmacovigilance 2: 135. doi:10.4172/23296887.1000135

Copyright: $\odot 2014$ Necho W, et al. This is an open-access article distributed under the terms of the Creative Commons Attribution License, which permits unrestricted use, distribution, and reproduction in any medium, provided the original author and source are credited. 


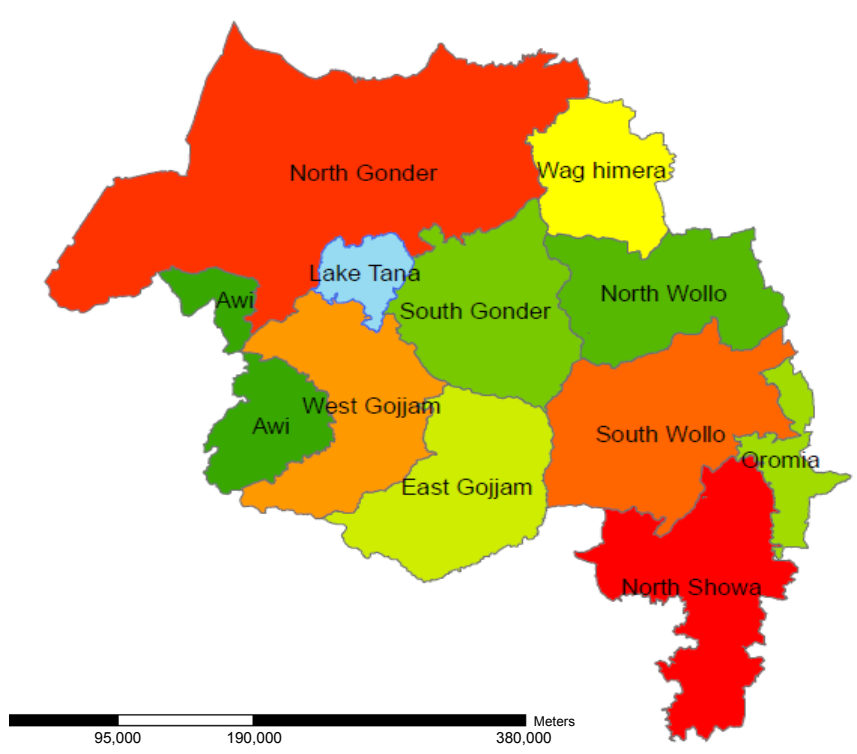

Figure 1: Map of Amhara region.

\begin{tabular}{|c|c|c|c|c|c|c|}
\hline \multirow{2}{*}{$\begin{array}{c}\text { Name of } \\
\text { hospital }\end{array}$} & \multicolumn{3}{|c|}{ Population Size } & \multicolumn{3}{c|}{ Sample size } \\
\cline { 2 - 7 } & Physicians & Nurses & $\begin{array}{l}\text { Pharmacy } \\
\text { personnel }\end{array}$ & Physicians & Nurses & $\begin{array}{l}\text { Pharmacy } \\
\text { personnel }\end{array}$ \\
\hline Borromeda & 3 & 23 & 7 & 3 & 18 & 6 \\
\hline Felegehiwot & 23 & 124 & 17 & 18 & 100 & 13 \\
\hline Mehalemeda & 5 & 25 & 6 & 4 & 20 & 5 \\
\hline Dessie & 23 & 110 & 15 & 18 & 88 & 12 \\
\hline Metema & 5 & 29 & 10 & 4 & 23 & 8 \\
\hline Finoteselam & 6 & 32 & 8 & 5 & 26 & 6 \\
\hline Debre Markos & 13 & 65 & 15 & 11 & 52 & 12 \\
\hline Debark & 5 & 16 & 7 & 4 & 13 & 6 \\
\hline Gondar & 73 & 200 & 18 & 59 & 160 & 14 \\
\hline Total & 156 & 624 & 103 & 126 & 500 & 82 \\
\hline
\end{tabular}

Table 1: calculated sample size of each hospital by profession using proportional sampling, according to population size of each hospital, Amhara region, 2012.

As there is no study on level of knowledge and factors associated with reporting in Amhara region, this study aimed to assess the knowledge, attitude and practice of health professionals towards an adverse drug reaction reporting and factors associated with ADR reporting.

\section{Methods}

This study was conducted in Amhara Region of Ethiopia, one of the regional states in the country. The region is divided into 11 zones and according to Bureau of Finance and Economic Development of the Amhara region, the 2012 projected population of the region was $19,239,302$. There are a total of 17 public hospitals in the region out of which 5 are referral hospitals. The region is bounded in the north by Tigray region, in the south by the Oromia region, in the east by the Afar region and in the west by Sudan (Figure 1).

Institutional based cross sectional study was conducted from May to November, 2012 to assess health professionals' knowledge, attitude and practice towards ADR reporting in Amhara region public hospitals. Health professionals (physicians, pharmacy personnel and nurses) who are working at the selected hospitals were included in the study

A two stage cluster sampling technique was used to select the study participants. For the purpose of this study 9 hospitals were selected using lottery method. The total numbers of health professionals in the selected hospitals were taken and proportional sample size was calculated for each so as to get the total sample size. The same procedure was used to make proportional allocation of physicians, nurses and pharmacy personnel in each hospital. Then using health professionals list by profession as a sampling frame 708 study participants was selected from randomly selected hospitals using a simple random sampling technique (Table 1).

\section{Data collection tools and procedures}

A structured self - administered questionnaire that captures essential data elements of the research question was developed. The questionnaire was adapted from similar studies and other materials investigating knowledge, attitude and practice of adverse drug reaction reporting among health care professionals [22-24]. It was designed to capture information regarding demographics of respondents, information regarding the knowledge, attitude and practice of spontaneous ADR reporting, barriers of reporting and suggestions towards a better ADR reporting culture. The questions were arranged and grouped according to the particular objectives of the study.

The questionnaire was finalized after a series of revisions by taking in to consideration the valuable comments from colleagues and advisors. The final version of the questioner comprised 35 items. Eight on demographic characteristics and general information on the reporting system, 11 items on knowledge, 10 on attitude and 6 on practice towards ADR reporting.

\section{Validity of the instrument}

Pretesting of the questionnaire was carried out in a similar setting to ensure its consistency and clarity at one of the hospitals in Amhara region. Five percent of the data collection instruments were pre-tested on subjects to whom the purpose of the study was explained. The results of the pretest were discussed with the facilitators and accordingly some corrections and rearrangements were made on the questionnaire.

\section{Data analysis}

The collected data were coded, entered and cleaned using EPI info version 3.5.1 and finally analyzed using SPSS version 16.0 software package by the principal investigator. Data analysis included all summary statistics to describe the study population in relation to the relevant variables.

Odds ratio was used to look for the strength of association of selected variables. Logistic regression was used to assess the effect of each explanatory variable on the outcome variable and to control the possible effect of confounders.

\section{Ethical consideration}

The ethical approval and clearance was obtained from Gondar university ethical committee. Permission was obtained from Amhara Regional Health Bureau, research and technology transfer core process and from the respective hospitals as well. Verbal consent of the study participants was obtained just before starting data collection. The study participants were informed about the purpose of the study and the importance of their participation in the study. The study subjects was informed that they can skip question(s) that they do not want to answer fully or partly and also quit the process at any time if they want to do so. All information filled was anonymous; there was no personal identification of the participants to ensure confidentiality of data filled. 


\begin{tabular}{|c|c|c|}
\hline Socio - demographic characteristics & Frequency $(n=625)$ & Percent (\%) \\
\hline \multicolumn{3}{|l|}{ Age } \\
\hline$<25$ years & 144 & 23 \\
\hline $25-34$ years & 350 & 56 \\
\hline 35 - 44 years & 73 & 11.7 \\
\hline$>44$ years & 58 & 9.3 \\
\hline \multicolumn{3}{|l|}{$\operatorname{Sex}(n=624)$} \\
\hline male & 311 & 49.8 \\
\hline female & 313 & 50.2 \\
\hline \multicolumn{3}{|l|}{ Type of profession } \\
\hline Physicians & 101 & 16.2 \\
\hline Nurses & 430 & 68.8 \\
\hline Pharmacy personnel & 94 & 15 \\
\hline \multicolumn{3}{|l|}{ Level of education } \\
\hline General practitioner & 81 & 13 \\
\hline B.pharm & 39 & 6.2 \\
\hline BSc. nurse & 191 & 30.6 \\
\hline Specialist & 19 & 3.1 \\
\hline MSc.in pharmacy & 1 & 0.2 \\
\hline Nurse diploma & 239 & 38.2 \\
\hline Druggist & 49 & 7.8 \\
\hline Others & 6 & 1 \\
\hline \multicolumn{3}{|l|}{ Year of service } \\
\hline$<5$ years & 403 & 64.5 \\
\hline $5-10$ years & 89 & 14.2 \\
\hline$>10$ years & 133 & 21.3 \\
\hline \multicolumn{3}{|l|}{ ADR related training } \\
\hline yes & 141 & 22.6 \\
\hline no & 484 & 77.4 \\
\hline \multicolumn{3}{|l|}{$\begin{array}{l}\text { Introduced to ADR at higher } \\
\text { institution trainings }\end{array}$} \\
\hline yes & 278 & 44.5 \\
\hline no & 347 & 55.5 \\
\hline \multicolumn{3}{|l|}{ Source of information on ADR } \\
\hline Standard text books & 427 & 68.3 \\
\hline Drug formulary & 210 & 33.6 \\
\hline Internet & 132 & 21.1 \\
\hline Medical representatives & 78 & 12.5 \\
\hline Others ${ }^{*}$ & 59 & 9.4 \\
\hline
\end{tabular}

*Journals, training documents and treatment guidelines

Table 2: Demographic characteristics of respondents on ADR reporting, Amhara region, Ethiopia 2012.

\section{Results}

\section{Demographic characteristics of respondents on ADR reporting}

A total of 708 health professionals participated in the study. However, 83 participants did not return and appropriately fill the questionnaire thus excluded from the analysis making the response rate $625(88.3 \%)$. About $49.8 \%$ of the respondents were male out of the 625 respondents. The mean age of the respondents was $29.1( \pm 8.1)$ with a range of 20 to 59 years. The median age was 27 years. The mean years of service was $7.4( \pm 8.3)$ ranging from 1 to 44 years of service. The median year of service was 4 years. Physicians accounted 101 (16.2\%) of the respondents, nurses $430(68.8 \%)$ and pharmacy personnel accounted $94(15 \%)$.
More than half $(55.5 \%)$ of the respondents were not introduced about the issue of ADR reporting system during their undergraduate study. Only one hundred forty one $(22.6 \%)$ of the respondents participated in any seminar or orientation training which includes topics on ADRs monitoring system. Four hundred twenty seven (68.3\%) of the study participants preferred books as their source of information about adverse drug reactions. But none of the respondents mentioned the national ADR reporting guideline as their source of information on ADR (Table 2).

\section{Health professionals' knowledge on an ADR reporting}

About one third of $(34.2 \%)$ the respondents had sufficient

\begin{tabular}{|c|c|c|}
\hline Knowledge items & $\begin{array}{l}\text { Frequency } \\
(n=625)\end{array}$ & Percent (\%) \\
\hline \multicolumn{3}{|l|}{ Pharmacovigilance definition } \\
\hline The science of therapeutic dose monitoring & 71 & 11.4 \\
\hline Regulating registration of new drugs & 65 & 10.4 \\
\hline Detection, assessment, prevention of ADR* & 327 & 52.3 \\
\hline Systematic way of detecting side effects & 162 & 25.9 \\
\hline \multicolumn{3}{|l|}{ Purpose of pharmacovigilance $(n=623$ ) } \\
\hline Identify safety of drugs * & 229 & 36.8 \\
\hline Detect the incidence of side effects & 394 & 63.2 \\
\hline \multicolumn{3}{|l|}{ Aware of the existence of ADR reporting } \\
\hline Yes & 268 & 42.9 \\
\hline No & 357 & 57.1 \\
\hline \multicolumn{3}{|l|}{ Responsible mainly in monitoring ADR report } \\
\hline $\mathrm{FMOH}$ & 103 & 16.5 \\
\hline FMHACA* $^{*}$ & 296 & 47.4 \\
\hline Universities & 25 & 4 \\
\hline EHNRI & 44 & 7 \\
\hline EPA & 157 & 25.1 \\
\hline \multicolumn{3}{|l|}{ Who are responsible in reporting ADR? } \\
\hline Physicians & 34 & 5.4 \\
\hline Nurses & 37 & 5.9 \\
\hline Pharmacy personnel & 47 & 7.5 \\
\hline $\mathrm{All}^{*}$ & 507 & 81.1 \\
\hline \multicolumn{3}{|l|}{ Aware of a drug removed from market } \\
\hline Yes & 210 & 33.6 \\
\hline No & 415 & 66.4 \\
\hline \multicolumn{3}{|l|}{ Know how to report } \\
\hline Yes & 174 & 27.8 \\
\hline No & 451 & 72.2 \\
\hline \multicolumn{3}{|l|}{ Aware of the yellow form } \\
\hline Yes & 134 & 21.4 \\
\hline No & 491 & 78.6 \\
\hline \multicolumn{3}{|l|}{ Which ADR Should be reported? } \\
\hline All ADRs* & 304 & 48.6 \\
\hline Series ADRs & 215 & 34.4 \\
\hline Prescriptions & 39 & 6.2 \\
\hline Unknown $A D R s$ and $A D R$ to new drugs & 48 & 7.7 \\
\hline ADR to vaccines & 19 & 3.0 \\
\hline \multicolumn{3}{|l|}{ Overall Knowledge } \\
\hline Sufficient & 214 & 34.2 \\
\hline Insufficient & 411 & 65.8 \\
\hline
\end{tabular}

* = correct knowledge

Table 3: Knowledge towards ADR reporting among health professionals, Amhara region, 2012. 
Citation: Necho W, Worku A (2014) Assessment of Knowledge, Attitude and Practice of Health Professionals towards Adverse Drug Reaction Reporting and Factors Associated with Reporting. J Pharmacovigilance 2: 135. doi:10.4172/2329-6887.1000135

Page 4 of 7

knowledge on the ADR reporting system. The mean score of knowledge is $5.1( \pm 2.2)$ with median 5 out of 11 knowledge items. About $63 \%$ of the respondents had not clearly identified the purpose of pharmacovigilance. Three hundred and fifty seven (57.1\%) of the respondents did not know about the existence of the ADR reporting system in Ethiopia (Table 3).

\section{Health professionals' attitude towards ADR reporting}

Respondents were asked to state the extent to which they agreed or disagreed with the questionnaire items. Based on this, the mean

\begin{tabular}{|c|c|c|c|c|c|}
\hline Attitude Items & SA(1) & Agree(2) & Undecided 3) & Disagree(4) & $\operatorname{SD}(5)$ \\
\hline Duty of health professionals & $170(27.2)$ & \multicolumn{2}{|c|}{$426(68.2) 12(1.9)$} & $12(1.9)$ & $5(0.8)$ \\
\hline Needs to be sure before reporting & $254(40.6)$ & $269(43)$ & $42(6.7)$ & $36(5.8)$ & $24(3.8)$ \\
\hline Reporting improves patient's safety* & $455(72.8)$ & $131(21)$ & $23(2.1)$ & $13(3.7)$ & $3(0.5)$ \\
\hline All ADRs should be reported & $263(42.1)$ & 208(33.3) & $62(9.9)$ & $70(11.2)$ & $22(3.5)$ \\
\hline Identify relatively safe drugs & $339(54.2)$ & $206(33)$ & $32(5.1)$ & $34(5.4)$ & $14(2.2)$ \\
\hline Reporting creates workload* & $49(7.8)$ & $142(22.7)$ & $51(8.2)$ & $212(33.9)$ & $171(27.4)$ \\
\hline Not important for the health care* & $31(4.96)$ & $40(6.4)$ & $33(5.3)$ & $204(32.6)$ & $317(50.7)$ \\
\hline Reporting ADR affects the patient confidentiality issue* & $55(8.8)$ & $116(18.6)$ & $65(10.4)$ & 193(30.9) & 196(31.4) \\
\hline A single report brings no difference* & $45(7.2)$ & 114(18.2) & $79(12.6)$ & $248(39.7)$ & 139(22.2) \\
\hline Legal liability issue affects reporting ${ }^{*}$ & $165(26.4)$ & $267(42.7)$ & $79(12.6)$ & $58(9.3)$ & $56(9)$ \\
\hline
\end{tabular}

SA - Strongly Agree, SD - Strongly Disagree

${ }^{*}=$ Negative statements on ADR reporting

Table 4: Attitude towards ADR reporting among health professionals, Amhara region, Ethiopia 2012.

\begin{tabular}{|c|c|c|}
\hline Practice & Number $(n=625)$ & Percent (\%) \\
\hline \multicolumn{3}{|l|}{ Ever reported ADR } \\
\hline Yes & 101 & 16.2 \\
\hline No & 524 & 83.8 \\
\hline \multicolumn{3}{|l|}{ Where reported?(n=101) } \\
\hline Manufacturers & 15 & 14.9 \\
\hline FMHACA & 28 & 27.7 \\
\hline DTC & 25 & 24.7 \\
\hline $\mathrm{FMOH}$ & 18 & 17.8 \\
\hline Others & 15 & 14.9 \\
\hline \multicolumn{3}{|l|}{ Presented ADR at morning meeting } \\
\hline Yes & 156 & 25 \\
\hline No & 469 & 75 \\
\hline \multicolumn{3}{|l|}{ Noted ADR on records } \\
\hline Yes & 238 & 38.1 \\
\hline No & 387 & 61.9 \\
\hline \multicolumn{3}{|l|}{ Reasons for low reporting of ADR ${ }^{*}$} \\
\hline Patient confidentiality issue & 92 & 14.7 \\
\hline Legal liability issue & 96 & 15.4 \\
\hline Not knowing where to report & 236 & 37.8 \\
\hline Do not know how to report & 271 & 43.4 \\
\hline Believe only safe drugs are marketed & 89 & 14.2 \\
\hline In difference & 77 & 12.3 \\
\hline Others & 57 & 9.1 \\
\hline \multicolumn{3}{|l|}{ Suggested solutions ${ }^{*}$} \\
\hline Use of reminders & 148 & 23.7 \\
\hline Face to face education & 273 & 43.7 \\
\hline Incentives to reporters & 128 & 20.5 \\
\hline Feedback information to reporters & 268 & 42.9 \\
\hline Other & 49 & 7.8 \\
\hline
\end{tabular}

¥Multiple responses were allowed

Table 5: Practice towards ADR reporting among health professionals, Amhara region, 2012.

score of attitude is $6.4 \pm 1.6$ with median 7 out of 10 attitude items. Health professionals were asked if they had considered reporting as their professional obligation. The majority of respondents 596 (95.4\%) strongly agreed or agreed that reporting ADR is the duty of health professionals. Five hundred and forty five (87.2\%) of the respondents strongly agreed or agreed that reporting adverse drug reactions is important to identify relatively safe drugs (Table 4 ).

\section{ADR reporting practice among health professionals}

Respondents asked whether they reported ADR during their 
practice as health professionals. A very small proportion of respondents 101 (16.2\%) had ever reported ADR they encountered during their professional practice. Of those health professionals who reported ADR, twenty eight (27.7\%) reported to FMHACA which is the responsible organization for monitoring and evaluating ADR. Less than half of the respondents 238 (38.1\%) had the experience of noting the ADR they encountered on their clinical records (Table 5).

\section{Multivariate analysis of factors associated with ADR reporting among health professionals}

In the multivariate analysis, being participated in ADR related trainings, being introduced with ADR during college or university education, level of knowledge are found to be significantly associated with ADR reporting $(\mathrm{P}<0.05)$. Age and years of service do not have statistically significant association with ADR reporting in the multivariate analysis. Health professional who participated in any ADR related training are about 2 times more likely to report compared with none trained ones [AOR: 1.82(1.10, 3.10)95\%CI]. The odds of reporting adverse drug reaction among health professionals with sufficient knowledge towards ADR reporting is 6 times more compared with those with insufficient knowledge [AOR: 5.99(3.61,9.94)95\%CI] (Table $6)$.

\section{Discussion}

This study gives pertinent information regarding knowledge, attitude and practice of health professionals towards adverse drug reaction reporting and factors associated with reporting. This study revealed that even though majority of health professionals have positive attitude towards ADR reporting, reporting among health professionals is low. This could be due to low level of knowledge and awareness among health professionals towards ADR reporting.
Health professionals with relatively better knowledge towards ADR are about 6 times more likely to report ADR compared with those with insufficient knowledge [AOR: $5.99(3.61,9.94) 95 \% \mathrm{CI}$ ]. This finding is in line with a study in Nigeria where lack of knowledge of the forms and procedures for reporting cited as a determinant factor for reporting [24]. Moreover, a systematic review on determinants of ADR reporting conducted in Spain confirmed that knowledge of health professionals appeared to be strongly related with reporting in a high proportion of studies [12]. Similar study in Spain also indicated that having the basic knowledge needed to report ADR as a determinant factor for ADR reporting [15]. This implied a certain level of knowledge is required for a health professional to report ADR. Those health professionals with sufficient knowledge have a higher chance of understanding the key procedures of reporting such as what to report, where to report and when to report that in turn encouraged reporting.

Another important finding of this study is that health professional who participated in any ADR related training are about 2 times more likely to report compared with none trained ones [AOR: 1.82(1.10, $3.10) 95 \% \mathrm{CI}$. This is in line with a study in Spain where participation in educational activities related to the detection and resolution of drugrelated problems positively associated with ADR reporting [15]. This might be due to the impact of training to improve the understanding of health professionals on the reporting scheme.

Formulary users as source of information for ADR have more chance to report ADR compared with non-formulary users [AOR: $1.71(1.05,2.79) 95 \% \mathrm{CI}]$. This can be explained by formulary users might have a higher chance of getting an insight on the consequences of ADR than the non-users. Besides to this, the current edition of the Ethiopian drug formulary included the yellow form for ADR reporting to encourage users to report ADR.

\begin{tabular}{|c|c|c|c|c|}
\hline \multirow[t]{2}{*}{ Variables } & \multicolumn{2}{|c|}{ ADR reporting } & \multicolumn{2}{|c|}{ OR(95\%Cl) } \\
\hline & Yes & No & Crude & Adjusted \\
\hline \multicolumn{5}{|l|}{ Age } \\
\hline$<25$ years & 15 & 129 & 1 & 1 \\
\hline $25-34$ years & 49 & 301 & $1.40(0.78,2.59)$ & $1.22(0.61,2.44)$ \\
\hline $35-44$ years & 21 & 52 & $3.47(1.66,7.26)^{* *}$ & $2.75(0.91,8.34)$ \\
\hline$>44$ years & 16 & 42 & $3.28(1.73,8.07)^{* *}$ & $2.05(0.58,7.29)$ \\
\hline \multicolumn{5}{|l|}{ Year of service } \\
\hline$<5$ years & 47 & 356 & 1 & 1 \\
\hline $5-10$ years & 20 & 69 & $2.20(1.23,3.93)$ & $1.95(0.97,3.92)$ \\
\hline$>10$ years & 34 & 99 & $2.60(1.59,4.26)$ & $1.52(0.57,4.0)$ \\
\hline \multicolumn{5}{|l|}{ In-service training on ADR } \\
\hline yes & 42 & 99 & $3.06(1.90,4.80)$ & $1.82(1.10,3.10)^{*}$ \\
\hline no & 59 & 425 & 1 & 1 \\
\hline \multicolumn{5}{|c|}{ Introduced to $A D R$ at higher education } \\
\hline Yes & 64 & 214 & $2.51(1.61,3.89)$ & $1.70(1.02,2.83)^{*}$ \\
\hline No & 37 & 310 & 1 & 1 \\
\hline \multicolumn{5}{|l|}{ Knowledge } \\
\hline Sufficient knowledge & 74 & 140 & $7.52(4.65,12.10)$ & $5.99(3.61,9.94)^{* *}$ \\
\hline Insufficient knowledge & 27 & 384 & 1 & 1 \\
\hline \multicolumn{5}{|l|}{ Formulary as a reference } \\
\hline Yes & 46 & 164 & $1.84(1.19,2.83)$ & $1.71(1.05,2.79)^{*}$ \\
\hline No & 55 & 360 & 1 & 1 \\
\hline
\end{tabular}

Adjusted for age, years of service, being introduced with ADR at higher education, in-service training on ADR, knowledge, formulary usage.

${ }^{*}=P<0.05,{ }^{* *}=P<0.001$ (all are significant)

Table 6: Multivariate analysis of factors associated with ADR reporting among health professionals, 2012. 
Based on the finding of this study, only one hundred forty one (22.6\%) of the respondents participated in any seminar or orientation training which includes topics on adverse drug reactions monitoring system. This indicates that a great majority of health professionals have no proper training on the issues related with ADR reporting. Majority of health professionals 427 (66.3\%) used standard books as their source of information about ADR. This might be due to the fact that other sources such as internet and formularies are not accessible to them.

Less than half of the respondents (47.2\%) recognized clearly FMHACA as a responsible organization to monitor and evaluate ADR in Ethiopia. This shows that more than $50 \%$ of respondents have no information on the regulatory authority. This is in line with a study conducted in Nigeria where less than half of respondents identified NPC in Abuja as a responsible office [8]. But a study in Malaysia indicated that almost all respondents (94.0\%) correctly identified the body that regulates ADR reporting in Malaysia. This could be due to a better access of information to health professionals concerning ADR reporting center in Malaysia. The implication of this study could be the reporting center in Ethiopia is not well familiar with health professionals. The qualitative part of this study also identified lack of familiarity on reporting system as an obstacle to report ADR. This may be due to less work done by the relevant organizations to advertise and promote the center through different media. The yellow form for ADR reporting was not familiar with the majority of the respondents (78.6\%). In a study in Nigeria, the standard yellow reporting form for adverse drug reactions was not known to a slightly less proportion (61.4\%) of respondents 24 . This implied that health professionals are not well sensitized on the reporting scheme by the concerned organizations.

A smaller proportion of respondents 101(16.2\%) had ever reported ADR they encountered during their professional practice. Of those health professionals who reported ADR, twenty eight (4.5\%) reported to FMHACA which is the responsible organization for monitoring and evaluating ADR. This study indicated that low reporting is a major problem among health professionals. The fact that majority of health professionals did not have basic knowledge on the reporting system might contribute to the low reporting practice. Poor feedback and limited options for reporting could also have additional impact on the reporting. This study is comparable with a study conducted in Lagos state and India $[8,23]$ and contrasted with a similar study conducted in Sweden where $60 \%$ of health professional experienced in reporting ADR to the relevant authority. This could be due to the fact that health professionals in Sweden might have a better level of understanding on the reporting scheme and there could be also good facilitation of reporting by relevant organizations in Sweden.

One of the important findings of this study is that even though $38.1 \%$ of respondents had the experience of noting the ADR they encountered on their clinical records, only less proportion of them (28.5\%) actually reported one or more ADR in their clinical practice. A study in Ethiopia that assessed barriers of ADR reporting showed that even though about $52.9 \%$ of health professional had encountered severe ADRs; they did not yet report them to anybody [9]. The findings from the qualitative part of this study also showed that health professionals encountered a number of ADRs during their clinical activities but only few were reported to the responsible organizations. This implied that if those health professionals who noted ADR they encountered on their clinical records are encouraged and supplied with the necessary forms, it would positively affect the reporting.

The following findings were found from the attitude of respondents towards ADR reporting. The larger proportion of respondents (95.4\%) felt that reporting is the duty of health professionals. This is the same as a study in Sweden where the majority (80.9\%) of the healthcare professionals were in opinion that ADR reporting is the duty of doctors, nurses and pharmacists [20]. To the contrary, $44 \%$ of respondents in a study in Iraq wrongly believed that ADR reporting is the duty of pharmaceutical companies and legal medical authorities [11]. This implied that health professionals have correctly understood that ADR reporting as part of their professional obligation. The larger proportion of respondents $(81.7 \%)$ concerned on the legal liability issue during reporting. This reflected that majority of health professionals working at hospitals in the region do not know that any reported case couldn't be used by any means as a source document for legal issues which is clearly stated on the ADR reporting guideline.

The study revealed a number of obstacles towards ADR reporting. Lack of familiarity on reporting system in general and the reporting center in particular were the two most important obstacles mentioned by $271(43.4 \%)$ and $236(37.8 \%)$ respondents respectively. This is consistent with similar study conducted in India [23]. The qualitative part of this study also cited similar barriers for ADR reporting. This implied that if relevant organizations work to minimize these barriers, it would be possible to improve the reporting rate. Absence of strong feedback mechanisms through different way from the relevant organization might discourage health professionals to report ADR. In addition, this finding implied that health professionals in the region have linked ADR reporting with legal and ethical issues. This indicated that the perception of the different obstacles by health professionals is an important factor in determining the causes of the underreporting and addressing these obstacles could lead to an improvement in spontaneous reporting. Difficulty concerning reporting mere suspicions, health professionals encouraged by one sided drug promotion and the belief that only safe drugs are allowed on the market are reasons that affect ADR reporting. Similar findings are also addressed as 'Inman's seven deadly sins' in a study conducted in Europe [25]. This studyidentified various solutions to improve reporting. Respondents suggested use of reminders and advertisements, conducting face to face education, and feedback from reporting center as important solutions to improve ADR reporting. A closer relationship between the doctors and the pharmacovigilance centre is suggested as a means of improving reporting. Continuous ADR educational program, training, and integration of ADRs' reporting into the activities of the health care professionals would likely improve ADR reporting. Other suggested measures to improve spontaneous reporting included regular meeting on ADRs related issues in each hospital. The importance of including pharmacovigilance related activity in undergraduate and post-graduate training program could have also paramount importance in improving reporting. Similar methods were also suggested as a solution to improve reporting in a study conducted in Nigeria, Malaysia, and Italy $[8,10,26]$.

\section{Strengths and Limitations of the Study}

\section{Strengths of the study}

- The quantitative data is supplemented by qualitative study to further explore barriers of reporting and possible suggested solutions

- The data collection instrument was pretested in similar setting, necessary corrections were made, and there was close follow up of the data collection process from principal investigator and facilitators.

- Internal comparison was deployed to assess factors associated with reporting even though the study design is cross sectional. 
Citation: Necho W, Worku A (2014) Assessment of Knowledge, Attitude and Practice of Health Professionals towards Adverse Drug Reaction Reporting and Factors Associated with Reporting. J Pharmacovigilance 2: 135. doi:10.4172/2329-6887.1000135

\section{Limitations of the study}

- As data were collected based on self-reported information, the possibility of reporting errors and recall biases could not be ruled out.

- In addition, the opinion of non responders could also affect the interpretation of the study.

- Underestimation of ADR reporting practice as all respondents had been taken as a denominator despite their status towards encountering ADR.

\section{Conclusions}

The study revealed low level of knowledge and low level of ADR reporting among health professionals towards ADR reporting. Knowledge of health professionals towards ADR reporting appear to be strongly related with reporting in this study. Awareness raising program on the ADR reporting system need to be designed to health professionals by relevant bodies and ADR reporting system need to be introduced and given an emphasis at higher institution training. On top of this, establishing strong feedback and increasing options of reporting would improve the reporting system.

\section{References}

1. Strandell J, Caster O, Bate A, Norén N, Edwards IR (2011) Reporting patterns indicative of adverse drug interactions: a systematic evaluation in VigiBase. Drug Saf 34: 253-266.

2. World Health Organization policy perspectives on medicines (2004) Pharmacovigilance: ensuring the safe use of medicines. World Health Organization, Geneva, Switzerland.

3. Edwards IR, Aronson JK (2000) Adverse drug reactions: definitions, diagnosis, and management. Lancet 356: 1255-1259.

4. Oshikoya KA (2006) Adverse drug reaction in children: Types, incidence and risk factors. Nigerian Journal of Pediatrics 33: 29-35.

5. Oreagba IA, Ogunleye OJ, Olayemi SO (2011) The knowledge, perceptions and practice of pharmacovigilance amongst community pharmacists in Lagos state, south west Nigeria. Pharmacoepidemiol Drug Saf 20: 30-35.

6. Sencan N, Altinkaynak M, Ferah I, Özyildirim A, Ceylan EM, et al. (2010) The knowledge and attitudes of physicians and nurses towards adverse event reporting and the effect of pharmacovigilance training: a hospital experience. Hacettepe University Journal of the Faculty of Pharmacy 30: 25-40.

7. Elkalmi RM, Hassali MA, Ibrahim MI, Widodo RT, Efan QM, et al. (2011) Pharmacy students' knowledge and perceptions about pharmacovigilance in Malaysian public universities. Am J Pharm Educ 75: 96

8. Oshikoya KA, Awobusuyi JO (2009) Perceptions of doctors to adverse drug reaction reporting in a teaching hospital in Lagos, Nigeria. BMC Clin Pharmaco 9: 14.

9. Rajyalakshmi G, Radhika T, Prasad N (2008) Antioxidant activity of red kino tree using frog heart model. Pharmacologyonline 3: $26-31$.

10. Elkami RM, Hassali MA, Ibrahim MI, Liau SY, Awaisu A (2011) A qualitative study exploring barriers and facilitators for reporting of adverse drug reactions among community pharmacists in Malaysia. Journal of Pharmaceutical Health Services Research 2: 71-78.
11. Hajebi G, Mortazavi SA, Salamzadeh J, Zian A (2010) A Survey of Knowledge, Attitude and Practice of Nurses towards Pharamacovigilance in Taleqani Hospital. Iran J Pharm Res 9: 199-206.

12. Lopez-Gonzalez E, Herdeiro MT, Figueiras A (2009) Determinants of underreporting of adverse drug reactions: a systematic review. Drug Saf 32: 19-31.

13. Hazell L, Shakir SA (2006) Under-reporting of adverse drug reactions : a systematic review. Drug Saf 29: 385-396.

14. Nichols V, Thériault-Dubé I, Touzin J, Delisle JF, Lebel D, et al. (2009) Risk perception and reasons for noncompliance in pharmacovigilance: a qualitative study conducted in Canada. Drug Safe 32: 579-590.

15. Irujo M, Beitia G, Bes-Rastrollo M, Figueiras A, Hernández-Díaz S, et al. (2007) Factors that influence under-reporting of suspected adverse drug reactions among community pharmacists in a Spanish region. Drug Saf 30: 1073-1082.

16. Herdeiro MT, Fiqueiras A, Polónia J, Gestal-Otero JJ (2005) Physicians' attitudes and adverse drug reaction reporting : a case-control study in Portugal. Drug Saf 28: 825-833.

17. Herdeiro MT, Figueiras A, Polónia J, Gestal-Otero JJ (2006) Influence of pharmacists' attitudes on adverse drug reaction reporting : a case-control study in Portugal. Drug Saf 29: 331-340.

18. Sweis D, Wong IC (2000) A survey on factors that could affect adverse drug reaction reporting according to hospital pharmacists in Great Britain. Drug Saf 23: $165-172$.

19. Gedde-Dahl A, Harg P, Stenberg-Nilsen H, Buajordet M, Granas AG, et al. (2007) Characteristics and quality of adverse drug reaction reports by pharmacists in Norway. Pharmacoepidemiol Drug Saf 16: 999-1005.

20. Ekman E, Bäckström M (2009) Attitudes among hospital physicians to the reporting of adverse drug reactions in Sweden. Eur J Clin Pharmacol 65: 43-46.

21. Drug Administration and Control Authority in collaboration with MSH/RPM plus/ SPS (2008) Report on the assessment of health care providers "knowledge, attitude and practice on Adverse Drug Reaction (ADR) reporting and its monitoring. Drug Administration and Control Authority, Addis Ababa, Ethiopia.

22. World Health Organization (2002) Safety of Medicines: A guide to detecting and reporting adverse drug reactions. World Health Organization, Geneva, Switzerland.

23. Desai CK, lyer G, Panchal J, Shah S, Dikshit RK (2011) An evaluation of knowledge, attitude, and practice of adverse drug reaction reporting among prescribers at a tertiary care hospital. Perspect Clin Res 2: 129-136.

24. Fadare JO, Enwere OO, Afolabi AO, Chedi BAZ, Musa A (2011) Knowledge, attitude and practice of adverse drug reaction reporting among healthcare workers in a tertiary centre in northern Nigeria. Tropical Journal of Pharmaceutical Research 10: 235-242.

25. Inman WH (1996) Attitudes to adverse drug reaction reporting. $\mathrm{Br} J$ Clin Pharmacol 41: 434-435.

26. Pellegrino P, Carnovale C, Cattaneo D, Perrone V, Antoniazzi S, et al. (2013) Pharmacovigilance knowledge in family paediatricians. A survey study in Italy. Health Policy 113: 216-220. 